\title{
Technology, Entrepreneurship, and Waiwai
}

\author{
Kelsey Amos and Donavan Kealoha \\ Whatever is Hawaiian, support 'em full on. \\ Israel Kamakawiwo'ole
}

Technology alone will not save us, but it can be a powerful part of the solution. What works in creating change is the power of convening diverse people to take innovative action based in kuleana to Hawai' $i$. When we pose questions, talk story, and investigate together, we build ideal conditions for cocreating the futures we want. True in the best of times, this is even more essential now, when global disaster and ineffectual or downright dangerous leadership lay bare the current system's inequalities, injustices, and dysfunctions.

Purple Mai'a started in 2013, when we saw a need for coding education for Hawai'i's youth. At that time, only three public high schools offered AP computer science-compared to thirty-three by 2018. We sourced our teachers and content from a community of local people who wanted to present technology in a relatable and culturally grounded way. Our students then felt empowered to learn and use technology for their own and their community's purposes.

We teach digital technology skills together with entrepreneurship because entrepreneurial action must complement progress in other arenas, such as policy, protest, and public education. If we don't pursue our own interests as Hawaiians and people of Hawai' $i$ in technology and entrepreneurship spaces, no one else will—or worse, someone will seek to do it for us.

\section{Innovate Technology by Grounding it in our own Community Needs and Cultural Wealth}

We have a vision of culturally and community-grounded technologists and entrepreneurs. We're not the experts at loko i'a and language resurgence, but we can be the engineers and innovators who design the water sensors that track tides and nutrient levels in the fishpond, or create the Google Chrome extension that makes crowd-source translation and dubbing of Netflix content into 'Ōlelo Hawai' i possible. We can be up to date on machine learning, blockchain, robotics, augmented 
reality, and IoT, while staying grounded in local community needs and efforts.

In this moment of COVID-19, how as technologists and entrepreneurs do we innovate in this space? We can see some things immediately.

- Increasing demand for online learning and access to Honolulu-based programs can become more equitable for rural communities. We must also address unequal access to computers, smartphones, and broadband.

- Will we see a greater demand for technology that connects students with 'āina virtually, via technologies like virtual reality and augmented reality, in a post-COVID-19 world where we are more attuned to limited mobility?

- COVID-19 has pushed many employers to embrace employees working from home. Will this trend continue, granting Hawai' i's workforce access to national or even global employment opportunities remotely, earning enough to continue to live in the islands?

COVID-19 has taught us that the future is unpredictable. We need to keep fostering pilina, because those connected to community are best positioned to respond quickly to community needs in a crisis. We also need what we call "communities of practice" to innovate toward the future we want. Communities of practice are often thought of as groups of people in a similar profession-web developers who exchange ideas, for instance, shaping trends and progress in their field. We feel that while differing widely in individual skills and talents, a community of practice can also share a grounding in kuleana to a place, and to care for 'āina and people. We can lift each other up, creating an amplification effect.

One example of how technologists and entrepreneurs might contribute to 'aina-based communities of practice is ahupua'a restoration across the pae 'âina.

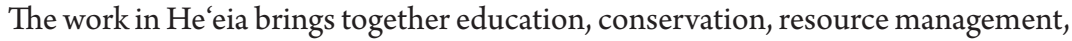
research, biocultural restoration, regenerative farming, and economic development. Technologists and innovators could support what kia' $i$ are doing, leveraging tech to amplify culture rather than leveraging culture for tech.

\section{Innovate Business Models for Community Wealth}

While solving problems locally, it's imperative to think globally, embracing opportunities to provide unique, homegrown, collaborative solutions to external markets, thereby realizing economic value that can be repatriated back to those communities who had a direct hand in birthing those ideas/solutions.

Many are already advocating for growing our technology and innovation industries, urging Hawai' $\mathrm{i}$ to become a model for sustainability and positive innovation. Having our tech industry bring in investment and high paying jobs is a worthy goal, but we must not forget that if we, as Hawaiians and people of Hawai' $i$, cannot shape how innovative solutions are created, marketed, distributed, and owned, we run the risk of settling for less-less value circulating in the economy 
with only low-wage or "service" technology jobs available, and tech that runs counter to our values. In response, we must build up our peoples' skills as we think about how Hawai' $\mathrm{i}$ benefits, who's leading, and whether we are just shifting around inequalities, or achieving a state of waiwai where less is actually more.

In her book Kaiāulu, Mehana Vaughan describes how in the recent past, people lived by becoming experts who managed their resources so well that they could always share. Her example is how lawai'a had to understand the fish and their environment, and learn how to mālama and manage them in order to have big catches, which would then be shared with everyone, without demanding immediate return. At the same time, people would receive what others shared from other resources.

The same should be true of building technology companies. We must become excellent entrepreneurs, while thinking creatively about how to structure companies seeking to make a profit (even if it's only one part of a triple bottom line), so that equity and ownership extend not only to all shareholders, but to stakeholders that include the organizations actually doing the work of biocultural resurgence, co-creating these market innovations with excellent entrepreneurs, and creating waiwai. To achieve our own purposes, we have to understand and innovate contemporary structures.

Shifted Energy is an enterprise with an innovative business structure that shares waiwai. The idea for this company originated in the work of local nonprofit Kanu Hawai' $i$ to create a more compassionate and resilient Hawai' i. Shifted developed a way to use water heaters as batteries for renewable energy, allowing apartment dwellers, and not just homeowners, to benefit from shifting to clean energy. When Shifted established its own company, along with the founders and early employees, Kanu received a significant percentage of ownership. This differs from the typical Silicon Valley model, where the majority of a company is owned by its founders, with a smaller percentage set aside for employees. As investors put money into a company to help build it, they too claim significant ownership. Only rarely is anything given to community organizations. Founders usually wait until they get rich to become philanthropists, and this sharing usually represents a small percentage of the wealth claimed by founders and investors.

Why not build in the giveback from the beginning? A percentage of equity or ownership of Hawai'i tech companies could be allocated to a collective of community organizations. Then, if there is an exit or liquidation event, or revenues get to the point that dividends are available, the collective members would realize economic benefit. We could define the percentages for ourselves, in this way reimagining social safety nets. We would have to acknowledge that we're aiming to create technology businesses that are home runs. Not all of them will be, but if some do go big, that success will help everyone else.

So Hawai' $i$ benefits - and if Hawaiians and people of Hawai' $i$ are leading, they'll make the right decisions about what kinds of innovations to pursue, and how to share the results. 


\section{Innovate the Ways We Live}

All this hoped-for economic growth from technology and innovation-funneled back into community and creating waiwai-must be paired with innovations in how we live. If we're all still pursuing a life of too much too fast, then success will come at the expense of someone else and their 'aina. But if 'äina and beloved community can meet people's needs, that is truly waiwai. Maybe we can live less individualistically, less dependent on markets, and with fewer material luxuries. And technology and entrepreneurship can help us shift to living in a $(\mathrm{k})$ new way, where less is more.

Kelsey Amos is a new mom and has a $\mathrm{PhD}$ in English from the University of Hawai' $\mathrm{i}$ at Manoā. A co-founder of Purple Mai'a Foundation, she grew up in Waipi'o Uka, graduating from Mililani High School, and receiving her BA from NYU.

Donavan Kealoha is a father, husband, entrepreneur, venture capitalist, and co-founder and Executive Director of Purple Mai'a, a nonprofit technology education startup providing indigenized tech education to underserved, high opportunity youth across Hawai' $i$. A proud product of Hawai'i public education, Donavan graduated from Lāna'i High School, and holds a BA and JD/MBA from the University of Hawai' $i$ at Manoā. 